\title{
Relational transformation and agonistic dialogue in divided societies
}

\section{Introduction}

Societies emerging from conflict and violence face enormous challenges. While achieving a peaceful political settlement marks a turning point in the recovery from violent conflict, it is evident that the transformative work required in the wake of a settlement remains long and arduous, often over decades or even generations. In most situations, an agreement to end the violence is not enough to transform a deeply divided society's underlying conflicts, which are rooted in history and identity. Divided or segregated institutions must also be transformed and, perhaps even more fundamentally, so too must relationships. Continued relational divides within a postviolent conflict society are likely to hamper efforts at institutional transformation and wider social reconstruction. Thus, in order to develop better capacities for dealing with these challenges, what is required in divided and post-violent conflict societies is long term, ongoing effort towards the transformation of underlying historical and relational conflict.

In many nations, efforts to address the legacies of the past have taken the form of high profile transitional justice measures, or techniques of reconciliation (Bashir and Kymlicka 2008, p.12), such as apologies, truth commissions or trials, which often become the public focus of a national reconciliation process. And although these techniques were, for the most part, developed in response to a recently-ended violent conflict, increasingly they have also been applied in stable settler colonial societies such as Australia, Canada and the United States, often in response to the complex, social relations that have emerged in the wake of colonialism. These measures can and do 
make an important contribution to reconciliation and conflict transformation in line with the various goals of these processes that Bashir and Kymlicka (2008) suggest. However, this article contends that the contribution made by these nation building reconciliation techniques can only ever be partial and must be supplemented by other transformational activity.

One such field of activity is the practice of inter-ethnic or inter-communal 'dialogue', which is emerging as an important reconciliation technique in ongoing conflict transformation work centred on the relational level. Dialogue is increasingly being recognised as an essential political practice that can do much to build relationships and expand understanding in divided societies as diverse as South Africa, Northern Ireland, Israel-Palestine, much of Latin America, and the settler colonies of Australia, New Zealand, Canada, and the United States. Dialogue, in the terms considered here, may take various forms, but can broadly be understood as a political intervention focused on creating and holding open the political space in which people in divided and postviolent conflict societies can engage across difference with a view to transforming their relationships.

Over the last several decades much theoretical and empirical scholarship has attempted to deepen our understanding of what practices are most effective in dealing with the multi level demands of conflict transformation work. Yet, as Alexander Hirsch (2012, p. 79) points out, despite the development of 'an entire sub-field of social and political thought', the question of how to reckon with violence, and the legacy of anger and loss that remains in its aftermath, remains far from settled. This is still an emerging and experimental field, where transitional justice and conflict transformation measures 'all 
too often fail to achieve the standard of reconciliation set for themselves.' At least one reason for such failure is the desire to sublimate, rather than confront, a violent history; protagonists are pressed to 'move on', to 'forgive and forget', in order to 'reunite a divided society through the soothing of tensions engendered between historical antagonists.' But as Hirsch also points out, a desire to avoid dealing with the past does little more than 'promote a collective social amnesia' leaving reconciliation and conflict transformation to pursue 'an assimilative resolution', a mode of 'quietist surrender by the victim to the perpetrator' rather than a mode of true justice (Hirsch, 2012, p. 79). These concerns are as relevant to now-stable settler colonial states as they are to nations more recently emerging from conflict (see Maddison 2011).

The nation-building approach to reconciliation aims to replace social divisions with a shared sense of nationhood. In this frame, reconciliation aspires to move members of a society away from the older, divisive identities that have previously defined them, towards a 'harmonious and integrated society' and a 'unified political community' (Bashir and Kymlicka, 2008, p. 15). This article contends, however, that such efforts are misdirected and unachievable, at least within any conceivable timeframe. Rather, the argument here is that, at best, groups in divided societies can aspire to an agonistic engagement, in which conflict across and about their deep, identity-based differences continues to define the relationship. While other modes of engagement based on, for example, deliberation, may be beneficial in assisting elite decision-making, agonistic approaches also have a role to play in smaller-scale civil society contexts aimed at relational transformation. Thus, agonism informs the analysis in the article both in terms of the goal of conflict transformation-meaning that reconciliation values ongoing non-violent conflict that enables passionate democratic contestation-and the 
techniques that contribute to this goal-in this case a specific model of dialogue (see Bashir and Kymlicka 2008, pp 12-17). In what follows I argue for the crucial importance of dialogical engagement across differences, an engagement that allows for an expanded understanding of the other, with the aim of sustaining peace and, over time, transforming the underlying conflict - not towards agreement, but in a direction that enables greater mutual understanding. This article sketches a model for this type of agonistic dialogue, which is described here as sustained, intensive, relational work, and which is considered to make an important contribution to conflict transformation in deeply divided societies.

\section{What is dialogue?}

In recent decades a normative theoretical consensus has begun to emerge that posits dialogue, of various forms, as a crucial element in conflict transformation efforts (see for example Taylor 1993, Tully 2008 inter alia). James Tully, for example, has stated unequivocally that reconciliation 'should be dialogical' (2004, p. 91). Yet despite a growing interest in the merits of dialogue, and in the face of a proliferation of dialogue projects in a range of contexts, as a field of political practice this mode of intervention remains surprisingly under-theorised. Conceptually, this remains a very muddy field, an indeterminate space in which the term dialogue is attached to a range of other forms of communication: dialogue and debate, dialogue and deliberation, dialogue and discussion, and so on. A wide array of dialogical methodologies only adds to this confusion. A lack of conceptual precision in the field means that many meetings, of all kinds, are labeled dialogue, almost to the point of rendering the category meaningless. Given the extent of 'dialogue' work currently underway around the world, including in some of the most intractable conflict situations, this lack of clarity is concerning, if not 
dangerous. Without conceptual clarity, which can in turn inform methodological and design choices, activities labeled 'dialogue' may potentially contribute to misunderstandings about goals and processes that could deepen rather than alleviate conflict. Thus, one aim in this article is to suggest the ways that greater conceptual clarity may contribute to the practice of dialogue, in the hope that this understanding might help in the application of this practice in divided social contexts. In what follows, this article draws out common elements of dialogical approaches as described in the extant literature, outlining what might be seen as an 'ideal type' rather than a guaranteed formula for success.

As a starting point, this article adopts the definition of dialogue developed by the United Nations Development Programme during their extensive work on dialogue processes ${ }^{1}$ in Latin America:

Dialogue is a process of genuine interaction through which human beings listen to each other with such depth and respect that they change based on what they learn. Each participant in a dialogue strives to incorporate the concerns of others in their own perspective, even when they continue to disagree. No participant gives up his/her identity, but each recognizes the validity of the claims of other human beings and therefore acts differently towards others (Cuentas and Linares Méndez, 2013, p. 9, emphasis added).

Dialogue is thus understood as 'a highly specialized form of discussion' (Yankelovich, 1999, p. 16), a 'uniquely democratic process' (Schoem et al 2001, p. 2), that can 'deepen and enrich democracy by enhancing the quality of public life and contributing to the development of civic mindedness among the people' (Bennett et al, 1996, p. 272). 
Dialogue in this mode is designed to create a space for meaningful and potentially transformative engagement between individuals and groups who may otherwise struggle to communicate effectively with one another (Pruitt and Thomas 2007). Fundamentally, as a form of political intervention, dialogue is intended to engage people in divided societies in a process of listening to one another deeply in ways that enable them to "penetrate behind the polite superficialities and defenses in which we habitually armor ourselves' (Yankelovich, 1999, p. 15) in order to challenge and change each group's views about the other group. While not generally aimed at achieving substantive agreement, dialogue focused on this form of relational transformation is intended to 'loosen the knot of misunderstanding' that has been tied together by what Oliver Ramsbotham (2010, p. 57) describes as 'radical disagreement.' According to Ramsbotham, radical disagreement means that 'substantive issues are surrounded by a penumbra of emotion that chokes off constructive communication and reduces verbal exchanges to a "conversation of the deaf." Parties to the conflict tend to 'blame each other, justify themselves, and endlessly repeat inherited mantras of hate.' But where many conflict resolution practitioners understand this type of disagreement as a 'terminus to dialogue', in fact it is often in precisely these contexts that an agonistic approach to dialogue may be most effective and most transformative.

Alongside this ideal type, the actual practice of dialogue is highly diverse. A study undertaken in South Africa identified 25 separate dialogue tools or methodologies (Bojer et al, 2006). The authors found some dialogue designs intended for small groups of 20 people, and others that could accommodate groups of up to 1200 or even 5000 in dialogue at the same time. The focus of some dialogue methodologies was on exploring and resolving conflict, while others were more concerned to find common ground. 
Some methodologies were designed explicitly as dialogues between groups, while others require each participant to be present only as individuals. The authors of this study also found, however, that there were some clear patterns across all these dialogue methods, which tended to focus on enabling open communication, honest speaking, and genuine listening; allowing people to take responsibility for their own learning; and creating a safe space in which participants felt able to surface their assumptions, question their previous judgments, and to change the way they think in order to generate new ideas or solutions that were beyond what had been imagined possible prior to the dialogue (Bojer et al, 2006, pp. 5-6). Many of these models of dialogue practice are complex and costly to mount, requiring the backing of a body such as the UNDP or substantial investment by the government or private sector. Each of these arrangements for funding and institutional support contains significant potential pitfalls. Discussion of these arrangements falls outside the scope of this article but is certainly an area that warrants further theorisation and scholarly attention.

Across definitions and models, dialogue tends to be clearly distinguished from other modes of communication such as debate and discussion. Harold Saunders (2001, p. 12) describes dialogue as 'more structured than a good conversation' but 'less structured than formal mediation or negotiation.' Dialogue is also considered to be the opposite of debate, as debate tends to involve a 'one sided pursuit of truth' (Dessel and Rogge, 2008, p. 211) where the intention is to listen for what is wrong or flawed in another person's argument in order to identify and expose these shortcomings. By contrast, dialogue focuses on 'listening for understanding', recognising that there may be several valid perspectives on the issues at hand, and thus trying to understand the situation from other points of view (Schirch and Sampt 2007, p. 7, Schoem et al, 2001). Generating 
'dialogical understanding' does not requires participants who may be from different and opposed cultural groups to reach any substantive agreement, but rather to 'listen to what the other says, and reach partial agreements about the meaning of the perspectives communicated' (James, 1999, p. 591). This approach asks participants to suspend their own assumptions in order to look at other people's opinions without making judgments, so that they might see what all of these opinions mean when taken together. This process results in the sharing of a 'common content', even if this does not equate with agreement, but from understanding this common content a group may be able to 'move more creatively in a different direction' (Bohm 2004 [1996], p. 30).

Dialogue is also proposed as a process of 'effective inquiry' (Koch 1996, p. 95). William Isaacs (1993, p. 25), a well-known scholar-practitioner of dialogue, defines dialogue as 'a discipline of collective thinking and inquiry, a process for transforming the quality of conversation and, in particular, the thinking that lies beneath it.' For Isaacs, the key concern in dialogue process is to uncover the 'shared, living fields of assumptions and constructed embodied meaning' that most people operate within. He contends that:

As people learn to perceive, inquire into, and allow transformation of the nature and shape of these fields, and the patterns of individual thinking and acting that inform them, they may discover entirely new levels of insight and forge substantive and, at times, dramatic changes in behaviour (1993, p. 25).

Bohm suggests that when people find their own basic assumptions are not being listened to, they can experience this as 'an act of violence.' Dialogue is intended to counter this epistemological violence, by creating a "collective way of opening up 
judgments and assumptions' (Bohm, 2004 [1996], p. 53). An emphasis on the 'democracy of inquiry' recognises that both parties have a contribution to make to understanding the problem (Koch, 1996, p. 104).

Different models of dialogue emphasise different aspects of both process and outcome. In the Bohmian model of dialogue, for example, it is crucial that people understand they are in a 'free' and 'empty' space where they are not expected to make any decisions or come to any conclusions. Indeed, Bohm goes so far as to suggest that a dialogue should not try to accomplish anything useful at all, because as soon as there is an attempt to accomplish a useful purpose there were will be an assumption about what is or is not useful, and this, in turn, will limit the dialogue (Bohm 2004, [1996], p. 20). Despite this view, however, one purpose that tends to be common to most models of dialogue is the building of relationships between previously alienated or opposed groups and individuals through the sharing of experiences, ideas, and information about concerns they have in common. This purpose informs the model of dialogue advanced below.

\section{Dialogue in divided societies}

Much of the discussion of dialogue thus far could be applied to dialogue on any topic, but the focus here is considerably narrower. Specifically, this article is concerned with dialogue that is political, democratic, and intended to address the particular challenges that characterise divided societies (see Guelke, 2012). This approach to conflict transformation is perhaps nowhere more important than in deeply divided societies in 
which one or more group has experienced historical exclusion and marginalisation. In these cases, as Bashir Bashir (2012, p. 132) points out, memories of oppression, exclusion, and violence become constitutive of individual and community identity, often defined against the other. Divergent histories of violence and conflict live on in everyday intercommunal relationships, often for generations after the violent conflict has ended. Informed by an agonistic framing, the work of conflict transformation, including dialogue, in such situations, is less about finding the 'truth' or some form of consensus about the history of the conflict, than it is about 'seeking accommodation between conflicting accounts in such a way as to make a conflict more liveable' (Little, 2012, p. 75). The aim must be to transform the conflict rather than to resolve it.

Facilitated dialogue is increasingly being used in situations where ethnopolitical conflict has produced these kinds of deep social divisions. The intent of dialogue in these situations is explicitly to build relationships through an open and respectful exchange of views and perspectives intended to create mutual understanding of the subjective reality of the other (Maoz et al, 2004, p. 1076). Harold Saunders (2001, p. 6) describes this type of dialogue as 'a public peace process' in which 'Citizens talking in depth together can become a microcosm of their communities, experiencing a change in relationships and then learning to design political actions and interactions that can change their larger bodies politics.' This type of political dialogue can be a precursor to more formal negotiation in situations of intense conflict, allowing people to talk with their adversaries outside of government in order to understand better what change might be possible in their existing, destructive relationships (Saunders, 2001, p. 13). Alternatively, dialogue in divided societies can facilitate greater understanding about 
the needs and priorities of other groups in ways that may go on to inform or influence public policy debate.

Dialogue in divided societies is inevitably a form of political dialogue. This term does not refer only to dialogue on 'political things' (although in divided societies that is likely also the case) but also to dialogue that is conducted 'politically'. Chantal Mouffe (2005, pp. 8-9) has distinguished between 'politics' as the various practices of conventional politics, and 'the political' as the ontological understanding of society as both constituted and instituted through spaces of power, conflict and antagonism. In this sense, defining what is or is not political dialogue has less to do with the objects of the dialogue than it does with the process itself, and it is on the grounds of process that most theorists distinguish political dialogue from other forms of dialogue (Esquith, 1996, p. 10). As Mouffe argues, a pluralist liberal democratic society 'does not deny the existence of conflicts but provides the institutions allowing them to be expressed in adversarial form...A well functioning democracy calls for a clash of legitimate democratic political positions' (2005, p. 30). Democratic dialogue is one such institution in which these political clashes can take place. This is particularly important in divided societies where dialogue processes often provide a rare space in which these clashes can occur between groups otherwise alienated from one another in quite profound ways.

Elements of the ideal type of dialogue outlined above would seem to support this approach to the practice of dialogue: the object of the process is not to achieve agreement, but rather to surface assumptions and expand understanding about the other group(s) in the divided society. Despite this, however, the author has observed that 
much of what takes place in the actual practice of dialogue is either explicitly labeled 'deliberation' or at least draws implicitly from some of the conceptual underpinnings of deliberative democracy, specifically those elements concerned with rationality and consensus. In contrast, the following section argues for a more agonistic approach to dialogue, an approach that moves away from the goal of consensus or agreement on the past, towards a more open ended, conflict-laden approach that allows an expansion of understanding without pressure to agree.

\section{Agonistic dialogue}

Agonistic pluralism as advanced by Chantal Mouffe (2000, 2005, 2007), William Connolly (1991, 2005), Bonnie Honig (1993) and others, is often opposed to the more deliberative orientation generally assumed to apply to dialogue work. Agonism involves 'a vibrant clash of democratic political positions' (Mouffe 2000, p. 13) meaning that the primary task of democracy is to convert antagonism into agonism and enemies into adversaries or, as Connolly (1991, p. x) puts it, to 'cultivate agonistic respect between interlocking and contending constituencies'. This does not happen, as deliberative democrats would have it, through argumentative persuasion, but rather through a democratic attitude that enables a contestatory, but respectful, engagement of adversaries across profound differences. The goal is not agreement or consensus, as establishing a consensus without exclusion is considered an impossibility (Mouffe 2007, p. 44). Agonists therefore affirm the central place of conflict in any democratic politics, a view that rests on a deep suspicion that anything resembling consensus 'too often become a way of coopting radical challenges to the dominant interests within a society' (Schaap, 2006, p. 257). Agonists, according to Sonali Chakravarti (2012, p. 
11), foreground the inherent struggles 'between forces, ideas and individuals' that are constitutive of political life, highlighting the ways in which consensus and rationality may limit this politics, and promoting an ideal of democracy that is marked by an 'epistemic openness' to difference and conflicting points of view. Agonists value both the creation of new political spaces and, within these spaces, efforts towards the development of new understandings of identity, although identity is understood as 'contingent, relational, and open to upheaval and change' (Chakravarti, 2012, p. 11).

Agonists have developed an important critique of the deliberative model. Deliberation is aimed primarily at decision-making, and carefully facilitated deliberation may assist pragmatic political elites to decide together even when they otherwise remain substantively opposed. In more citizen-based forums, however, many divided societies may be poorly equipped to deliberate at the social level. According to the agonistic view, a central problem with deliberation as it might be applied to dialogue in divided societies is that it is unable to handle deep, identity-based societal differences. While people in divided societies may be able to deliberate about competing needs and interests, agonists contend that this understanding of difference is inadequate in many contexts, but most especially in divided societies where differences are fuelled by identity. Even where identity is recognised as contingent and produced by complex power relations, in the context of social and historical division identities tend to be passionately defended, often understood as the very root of the conflict or division. Deliberation, by definition a rational activity, is thought unable to handle such passions. Thus, what is at stake in the agonistic critique of deliberative democracy, according to Mouffe, is 'the need to acknowledge the dimension of power and antagonism and their 
ineradicable character', along with the crucial role that this dimension plays in the formation of collective identities (Mouffe, 2007, p. 40). ${ }^{2}$

An agonistic view of dialogue can be seen as precisely the type of democratic institution that Mouffe imagines making room for dissent within a pluralistic democracy (2007, p. 43), and this type of institutionalised practice may prove even more important in divided societies. Contrary to the views of deliberative democrats who view identitybased disagreement as inherently dangerous, Mouffe suggests that accepting the inevitability of conflict based on identity, may in fact 'contribute to defusing the potential for violence that exists in every construction of collective identities' (Mouffe 2007, p. 44, Little 2007, p. 155). Conceived in this way, disagreement may be understood as 'the lifeblood of a democratic order' and 'essential to democratic engagement across difference' (Little 2007, pp. 154-5). Dialogue in this agonistic mode may contribute to a pluralism that 'valorises diversity and dissensus', rather than to a public sphere that aims to eliminate them, finding in these conflicting identities and the processes that aim to engage them 'the very condition for a striving democratic life' (Mouffe, 2007, p. 44).

Agonistic dialogue seeks to do more than have people work through a shared problem in search of consensus about its solution. Approaches to inter-group communication that focus on consensus tend to avoid 'exploring or altering underlying patterns of meaning' (Isaacs, 1993, pp. 26). In contrast, dialogue with an agonistic orientation focuses on expanding understanding by 'surfacing fundamental assumptions and gaining insight into why they arise' (Isaacs, 1993, pp. 26-7). It is intended that dialogue participants make a serious and genuine effort to understand others' concerns, even though deep disagreements may persist. In divided societies this cannot entail an 
avoidance of the 'explosive' issues of history, politics, and identity. Dialogue must address these concerns, not with a view to finding consensus, but with the intent of transforming the antagonist in the conflict into a 'complete, full-bodied entity' with whom it might be possible to sympathise (Eisikovits, 2010, p. 144).

Ganesh and Zoller (2012, p. 67) have described three orientations towards dialogue: collaborative, co-optive, and agonistic. They draw distinctions between these orientations based on the underlying assumptions about conflict, power, and the role of difference that are hidden in each, arguing that consensus-oriented methods of dialogue have the effect of 'delegitimizing' certain forms of 'activist communication.' In contrast, they also argue in favour of an agonistic approach, which enables a broader range of communication styles by 'acknowledging issues of power and conflict as a central feature of dialogue.' Agonistic dialogue highlights the shifting nature of relationships concerned with power, identity, and vulnerability, and continues to privilege conflict as a crucial and potentially productive element of social change (Ganesh and Zoller, 2012, p. 77). Indeed, in struggles for justice, it may be the case that more rather than less conflict is required to truly dredge the depths of a disagreement, facilitate deep learning about the other, and therefore ensure that needs are fully addressed. Rather than bracketing or avoiding conflict, the aim in dialogue work is to 'transform actually or potentially violent conflict into non-violent forms of social struggle and social change' (Ramsbotham, 2010, p. 53). This is a pragmatic approach to conflict that highlights changing power relationships and the mobilisation of identities, while remaining alive to concerns with justice and material needs (Ganesh and Zoller, 2012, p. 77). 
Participants in dialogue often welcome the opportunity to explore their conflicts fully. Practitioners suggest that it is often the case that an enlarged understanding of other groups and participants in dialogue can lead to a greater recognition of difference, rather than a greater sense of unity as is often imagined. For example, in studying a series of community dialogues intended to improve race relations in the deeply divided city of Madison in the United States, Katherine Walsh found that rather than minimising conflict through developing 'overarching identities with one another', as she had expected, participants in the dialogue 'were finding out just how not close they were to others.' Walsh had expected that participants would 'grope for shared values, experiences, identities, memberships - something on which they could find common ground.' Instead she found that the sessions 'were busy with the recognition and understanding of difference' (Walsh, 2007, p. x). A similar dynamic can be found in dialogue processes in post-violent conflict societies such as Northern Ireland or South Africa, where opposing groups remain committed to the articulation of their social and cultural differences. In such cases the pursuit of consensus would be both impractical and undesirable, inevitably seeing some participants co-opted, and differences suppressed for the sake of broader agreement.

In terms of the type of transformative learning that is available to dialogue participants, it is evident that such learning takes place through far more than the rational exchange of argument as envisaged by deliberative democrats. An agonistic approach to dialogue allows greater scope for people to express the full range of their passions-anger, hatred, jealousy, pride, joy and so on. As John Forester points out, participants in dialogue learn more about each other from the way they make claims rather than from the contents of the claims themselves, as he argues, 'From the reasons they give, we 
learn about what others want or believe. But from the way they talk and act, from their style, we learn about who they are' (Forester, 1996, p. 310). The mode of communication available in dialogue - as opposed to the reasoned argument that is valued in deliberation - also suggests a more agonistic approach that values the ways in which, for example, stories can supplement a 'limited rationality' (Forester, 1996, p. 311). Thus, the rituals of telling and listening to stories can work to 'transform identities, agendas, and perceptions of value in the world' (Forester, 1996, pp. 314-6). As dialogue practitioner Adam Kahane has suggested, the creativity that is part of working in dialogue:

...requires all of our selves: our thoughts, feelings, personalities, histories, desires, and spirits. It is not enough to listen rationally to inert facts and ideas; we also have to listen to people in a way that encourages them to realize their own potential and the potential in their situation (Kahane, 2004, p. 90).

Kahane, who specialises in working in divided and post-violent conflict settings, maintains that limiting the style of communication available in dialogue to polite and rational argument may be wholly inadequate, 'leaving a dangerous reality unaddressed and unaltered' (Kahane, 2004, p. 57).

Still, despite these aspects of dialogue that seem to lend themselves to a more agonistic understanding, there is much in what dialogue promotes that does not accept the agonistic view of the permanence of conflict. Indeed, much of what is written about the type of learning that is available through dialogue emphasises the capacity for relationships to be transformed through a process of learning about 'the other'. In this sense, dialogue neither strives towards consensus, as deliberative democrats might 
hope, but neither does it accept that conflictual relationships are immune to dialogical transformation through enlarged understanding and the suspension of assumption.

Ultimately, however, if we return to the question of the goal of reconciliation as discussed above, it seems that the practice of dialogue must draw more from an agonistic than a deliberative understanding of democracy. The purpose of dialogue is to expand the understanding of conflict in order that communities and nations can 'live together productively, even harmoniously, with conflict' (Schoem et al, 2001, p. 15, emphasis added). The goal is not to resolve or do away with conflict through the discovery of consensus, and where a consensus might emerge it is most likely to be treated as partial, fragile, contingent, and temporary.

Here, then, we can also see a distinct difference between this mode of dialogue and the sort of positive contact and prejudice reduction work that has typified much relational work in divided societies. Practices that have focused on positive contact have tended to prioritise the creation of intergroup harmony and the development of friendships and interpersonal relationships. While these approaches no doubt contribute to demystifying the unknown 'other' community, it is also possible that contact work will 'avoid sociopolitical analysis, promote false assumptions of equality, and mute motivations for social change' (Nagda et al, 2012, p. 215). In other words, where contact work seeks to avoid conflict, agonistic dialogue seeks to engage it, seeing in an agonistic engagement a greater possibility for understanding, if not agreement. The final section of this article outlines an agonistic model for dialogue aimed at conflict transformation in divided and post-violent conflict societies. 


\section{Dialogue as sustained, intensive, relational work}

The model of dialogue that is proposed in this article has three key requirements that allow for its agonistic orientation. The first requirement is that such a practice is sustained over time. Dialogue is 'a process not an event', based on the recognition that only time spent together in extended discussion can produce the 'depth of meaning, the nuance of difference, and the fulfillment of connection' that dialogue promises (Schoem et al, 2001, p. 6). This type of sustained dialogue is intended to change conflictual relationships over time, focusing not just on the problems that have brought groups to dialogue, but on the underlying relational dynamics that contribute to these problems. The focus is on changing relationships rather than making policy decisions, and is designed specifically for groups and communities experiencing deep-rooted human conflict or tension across a range of ethnic, racial, religious, historic, material or personal causes (Saunders, 2001, p. 81, Wayne, 2008, p. 452). Saunders (2001, p. 12) describes this process as involving 'systematic, prolonged dialogue among small groups of representative citizens committed to changing conflictual relationships, ending conflict and building peace.' Clearly such commitment requires a degree of willingness among groups in the society prepared to engage in a long term process - a condition that is found surprisingly frequently in even the most divided of societies, although it will not be present on all occasions. Where it is present, the opportunity to sustain the dialogue over time may 'provide one of those rare spaces in which people can call time-out from everyday problems to ask: "What are the real problems in our relationship that make issues seem so intractable?"' (Saunders, 2001, p. 87). 
Where it is possible, sustaining dialogue over time allows participants to deepen their understanding of one another, attending to nuanced differences, and finding connections and shared experience that are only evident after extended discussion. Over time, and with careful facilitation, participants may learn to trust each other even as they continue to passionately disagree, becoming more confident to probe difficult issues, challenge themselves and each other, to express a fuller range of emotions, and to 'see beyond group boundaries to both structural conditions and intergroup concerns' (Schoem et al, 2001, p. 6). The notion of sustained activity is 'implicit' in the definition of dialogue: 'With commitment, people realise they can confront tough issues and know the conversation will continue and move forward the following week with the group intact' (Schoem et al, 2001, p. 8). Thus, from a dialogical perspective, a lack of agreement can be seen as a stimulus for sustaining engagement and interaction over time, rather than a disadvantage to the process.

The agonistic model of dialogue proposed here also requires an intensive level of engagement with both process and content. In the context of divided societies, dialogue is especially challenging and reliant on highly skilled facilitators to maintain an intensive focus and engagement among participants who are profoundly alienated from one another. John Dryzek points to one of the key reasons that dialogue has been so widely taken up in divided societies, that is, that one of the features of this type of social division are the 'mutually contradictory assertions of identity' which constitute 'arguably the toughest kinds of political issues' (Dryzek, 2005, p. 219). The historical legacy of conflict most often leaves 'a very deep wound' that 'goes to the very core of the group's identity and being' (Bashir, 2012, p. 129). Thus, participants in dialogue in divided societies bring with them to the process 'all the competitive behaviours, power 
struggles and negative perceptions that characterize such groups', which in the hands of a poor facilitator will merely be replicated in the dialogue itself (Maoz et al, 2008, p. 1077) thereby producing or reproducing a form of epistemic violence. Often dialogue processes are co-facilitated by pairs of trained facilitators who represent the different social or cultural identities of the groups participating in the work (Dessel and Rogge, 2008, p. 211). As Daniel Yankelovich suggests, 'the most frequent reason that dialogue fails is simply that it is not done well' (1999, p. 17). It takes skilled facilitation to draw participants in dialogue into a deep and intensive process that does not merely skate over the conflicts that are present among the group.

Oliver Escobar (2011, p. 14) distinguishes between conflict in dialogue, which he sees as 'an indispensible part of democratic life' and confrontation, which stifles or stalls conversation and therefore 'hinders mutual learning, fosters shallow exchanges, accentuates polarization, and leaves the issues underexplored.' But while confrontational dynamics should be avoided, this does not mean avoiding conflict. Escobar insists that, in dialogue practice, practitioners should aim 'to frame conflictive issues not as stumbling blocks or no-go zones, but as areas that require further exploration through collaborative investigation.' To guide participants into these areas, skilled facilitators bring a set of key pedagogical tools. These include content learning, which may involve activities such as set readings about the historical and contemporary nature of the conflict along with personal narratives of individual experience, writing tasks, and questions designed to stimulate discussion and reflection. Facilitators will engage the group in structured interactions, working to establish the group's rules of engagement and building in structured activities that illustrate the process of critical engagement. Finally, through facilitative guidance the group can be supported to 
improve their intergroup communication with maximum participation (Nagda et al, 2012, p. 211). There are also risks inherent to this role that require further exploration and problematisation; work that to date has primarily been undertaken by communities of practice among practitioners themselves or in 'how to' guides for dialogue work (see for example Holloway 2004), rather than through scholarly analysis or theorisation. Nevertheless, this type of skilled facilitation is essential for helping groups of dialogue participants to develop and maintain the intensity of their work.

Most centrally, this model of dialogue is relational in focus. Agonistic dialogue focuses not just on issues or topics of disagreement, but is concerned with the dynamics of the relationships underlying those issues. In the context of deeply divided societies, and regardless of whether the division is the result of long-ago historical conflict or more recent violence, the underlying conflict that needs to be addressed almost always involves conflict between identities (Schaap, 2006, p. 262), meaning that it is the task of dialogue to engage these identities in relationship. The emerging focus on dialogue in conflict transformation work underscores the significance of relationships as a site for analysis and change. As Nagda et al suggest:

To address identity-based conflicts, relationship building is valued over immediate resolution; recognition of human impact of conflict is valued over managing solutions; and retooling with new ways of thinking and relating in the context of justice is valued over existing conflict resolution methods that maintain the power hierarchy (Nagda et al, 2012, p. 226).

While governments or more formal political actors may deliberate or negotiate around issues and interests, citizens tend to focus more on relationships. And while both tracks are important, until the relationships in a divided society are changed 'deep-rooted 
conflicts are not likely to be resolved' (Saunders 2001, p. 32). Thus, the focus of the type of dialogue advanced here is not on policy or outcome, but is entirely relational.

The emerging focus on the relational dynamics of divided groups and on 'relationship as a site of change' demands 'an intentional communication process' (Nagda et al 2012, p. 213) that enables participants to deal explicitly with differences, power, and conflict. Again, although a preparedness to engage in work focused on relational dynamics is found surprisingly frequently in even the most divided of societies, it will not be present on all occasions. Nevertheless, where it is present, the relational approach considers ways in which relationships can change so that divided groups can work together to understand their specific problems (Saunders, 2001, p. 88). Members of both dominant and nondominant social groups have reported positive experiences from participating in intergroup dialogue, particularly where the power differentials inherent to these relationships are acknowledged, and where the dialogue process 'incorporates recognition of systemic imbalances of power, perceptions, and goals' between groups (Dessel and Rogge, 2008, p. 214).

Most models of sustained intergroup dialogue suggest a number of stages through which group relationships may be guided. For example, in what Nagda et al (2012, p. 215) describe as a 'developmental stage approach', a group is guided through four stages:

1. Group beginnings: Forming and building relationships

i. Acknowledging the context of the conflict

ii. Building a container for their dialogical engagement

2. Exploring differences and commonalities of experiences 
i. Exploring commonalities and differences in experiences of conflict

ii. Contextualising conflict in systems of inequalities

3. Exploring and dialoguing about 'hot' topics

i. Exploring dimensions of conflict in personal and political issues

ii. Engaging in disagreements and differences on political issues

4. Action planning and collaboration

i. Strengthening collaborative relationships to impact upon conflict

ii. Engaging with conflict in the context of change (2012, p. 215).

These authors suggest that at each stage of their model 'relationship-building processes are intensified and so too are the critical processes of understanding how power often undergirds conflicts as well as understanding the possibilities for enacting social change' (Nagda et al 2012, p. 215). In other words, the dialogue must be relational, intensive, and sustained over time in order to guide participants towards a deeper understanding of their conflict and their future options.

There are, quite obviously, profound risks in this sort of work, particularly in the context of intractable, radical disagreement. Indeed, Oliver Ramsbotham goes so far as to suggest that radical disagreement does not allow the conceptual or emotional space for the type of listening that is required in dialogue work. He argues that processes focused on increasing understanding and trust among participants assume that more understanding will lead to more trust. Such an assumption 'omits the possibility that more interchange will deepen mistrust, or that more understanding will make it even 
clearer to participants why they hate each other' (2010, p. 80). Certainly this approach will not be suitable for all people in all situations. Paul Healy points to the importance of openness in dialogue, which includes 'a willingness to put our own initial prejudgments and prejudices at risk.' This type of risk entails a 'radical shift' away from the need to persuade others of the merits of our own position to instead allow our own prejudgments 'to be genuinely called into question.' Without this shift and the commitment to greater openness that it entails, Healy contends, 'we cannot claim to be treating the other as a real partner in dialogue' (2011, p. 303).

Different groups in different societies may be more or less ready to engage in this work and take such risks. Activity such as this is rarely comfortable and only very occasionally is it the kind of 'feel good' exercise that dialogue is sometimes parodied as being. Rather, dialogue provides an unusual opportunity to 'engage conflict safely and fully' among groups that may have long histories of division and power imbalance. And although this may ultimately produce an expanded understanding of the other, in the process participants often find themselves feeling vulnerable, anxious and fearful (Schoem et al, 2001, p. 12). Unlike potentially 'safer' forms of interaction across difference and division such as, for example, negotiation, dialogue requires participants to reveal their deep hopes, fears and interests (Saunders, 2001, p. 84).

But within these risks there is enormous promise. Through sustained dialogue 'about and across differences', participants may be able to build relationships, learn about their different experiences of conflict, and how these experiences are enmeshed with relations of power. Over time, participants may also learn to recognise the ways in which their historical and contemporary conflicts play out both within the dialogue 
setting and in the wider community (Nagda et al, 2012, p. 213). Indeed, as small groups of citizens participate in agonistic dialogue processes, they also take their new understandings about other groups in their divided societies out into the broader polity, potentially contributing to a greater democratic transformation over time. Thus, although no panacea to deep-rooted historical conflict, this model of dialogue would seem to offer much to the ongoing challenges of conflict transformation in divided societies.

\section{Conclusion}

While the importance of making peace cannot be underestimated, neither should this moment be understood as the end of the process. Long term conflict and violence inevitably leave a legacy of hatred and distrust, a need to lay blame, and the desire for revenge. If these experiences are not addressed it is likely that violent conflict will resurface, regardless of any formal settlement reached (Nadler, 2012, p. 291). Thus, both before and after a political settlement is achieved, and possibly for several generations afterwards, it is likely that ongoing work designed to surface and address underlying structural and cultural violence through a focus on transforming identities and relationships will be of benefit. The aim, however, is not to rid a society of conflict but rather to transform the nature of that conflict. Recognising that conflict is at the heart of 'the political' (Mouffe 2005) the aim is to transform 'violent conflict into nonviolent forms of ongoing political struggle' (Ramsbotham, 2010, pp. 52, 211). Conflict remains central to a peaceful but democratically engaged polity. 
In many countries that have been divided by violent conflict, inter-ethnic/intercommunal hate and mistrust, exclusion, discrimination, and the experience of real and perceived threats to culture, person and property persist. Segregation and sectarianism have become institutionalised and normalised within society and politics, leaving little capacity for interaction between groups. Undoing these legacies of violent conflict will take effort. When conceived in these terms, as Schaap suggests, a process of dialogue that aims to contribute to these efforts must be an 'unsettling experience', precisely because 'it seeks to enact a radical break with the social order than underpinned the violence of the past' (Schaap 2006, p. 272). There are many reasons to believe that divided and postconflict societies around the world would benefit from this kind of unsettling process.

Nevertheless, as Ramsbotham also points out, there are some conflicts that may simply be resistant to transformation, where disagreement is framed in rigid and contradictory terms, and where enemies are unwilling to live with these contradictions (2010, p. 83). Thus, according to Ramsbotham, while what he calls the 'discursive conflict transformation programme' is indeed 'innovatory and potent', this potential has limits and, in cases of radical disagreement, dialogue cannot provide the sought after remedies precisely because 'the clash of discourses threatens to burst its frameworks asunder' (2010, p. 91). In such cases Ramsbotham in fact takes agonistic dialogue a step beyond the agonistic pluralism offered by Mouffe, in which the 'raw antagonism and violence' of 'the political' is 'tamed within the democratic agon'. Instead, what Rambsotham describes as agonistic dialogue maintains space for antagonism within its framework of verbal exchange, making the space of dialogue a process of 'intense political struggle in general without trying to distinguish yet between domesticated and undomesticated 
versions' (2010, p. 94). There is more to do to fully differentiate within models of agonistic dialogue to determine what practice will be most effective where.

This article has been concerned with the relational level of conflict transformation, specifically with the contribution that an agonistic mode of sustained, intensive, relational work might offer to divided societies. There is no argument here to suggest that relational work alone can transform historical conflict and deep social division, nor does this article contend that agonistic engagement cannot be complemented by other modes of discourse such as deliberation. Deliberation will continue to make important contributions to future oriented decision-making, although in divided societies this will need 'to be supplemented with primarily backward-looking and specifically tailored processes of reconciliation' (Bashir 2008, p. 67). The agonistic approach to relational transformation outlined here contributes to democratic practice through recognising the inevitability and permanency of conflict. This view suggests that this type of conflict transformation work can expand the understanding of conflict in order that communities and nations can 'live together productively, even harmoniously, with conflict' (Schoem et al 2001, p. 15, emphasis added). Conflict is not resolved nor eliminated, and relationships are not 'restored' as in a more normative sense of reconciliation. Rather, as a contribution to struggles intended to transform underlying social conflict in deeply divided societies, agonistic dialogue that is sustained, intensive, and relational in focus may help to transform enemies into adversaries prepared to engage in the type of nonviolent conflict that is sustaining of democratic engagement.

\section{References}


Bashir, Bashir and Kymlicka, Will (2008), 'Introduction: Struggles for inclusion and reconciliation in modern democracies', in Will Kymlicka and Bashir Bashir (eds) The politics of reconciliation in multicultural societies, Oxford University Press, Oxford, pp. 1-24.

Bashir, Bashir (2012), 'Reconciling historical injustices: Deliberative democracy and the politics of reconciliation', Res Publica, Vol. 18, No. 2, pp. 127-143.

Bennett, Stephen Earl, Fisher, Bonnie, and Resnick, David (1996), 'Speaking of politics in the United States: Who talks to whom, why, and why not', Poznań Studies in the Philosophy of the Sciences and the Humanities, Vol. 46, pp. 263-293.

Bohm, David (2004 [1996]), On dialogue, Routledge Classics, New York.

Bojer, Marianne, Knuth, Marianne, and Magner, Colleen (2006), Mapping dialogue: A research project profiling dialogue tools and processes for social change, Pioneers of Change Associates, Johannesburg.

Chakravarti, Sonali (2012), 'Agonism and the power of victim testimony', in Alexander Keller Hirsch (ed), Theorising post-conflict reconciliation, Routledge, London, pp. 1126.

Connolly, William (2005), Pluralism, Duke University Press, Durham. 
Connolly, William (1991), Identity/difference: Democratic negotiations of political paradox, University of Minnesota Press, Minneapolis.

Cuentas, Mirna Ángela and Linares Méndez, Anaí (2013), Practical guide on democratic dialogue, Crisis Prevention and Recovery Practice Area, United Nations Development Programme Regional Centre for Latin America and the Caribbean, Panama City.

Dessel, Adrienne and Rogge, Mary (2008), 'Evaluation of intergroup dialogue: A review of the empirical literature', Conflict Resolution Quarterly, Vol. 26, No. 2, pp. 199-238.

Dryzek, John (2005), 'Deliberative democracy in divided societies: Alternatives to agonism and analgesia', Political Theory, Vol. 33, No. 2, pp. 218-242.

Dryzek, John and Niemeyer, Simon (2006), 'Reconciling pluralism and consensus as political ideals', American Journal of Political Science, 50(3) 634-649.

Escobar, Oliver (2011), Public dialogue and deliberation: A communication perspective for public engagement practitioners, Edinburgh Beltane, Edinburgh.

Esquith, Stephen L. (1996), 'Political dialogue and political virtue', Poznań Studies in the Philosophy of the Sciences and the Humanities, Vol. 46, pp. 9-22. 
Ganesh, Shiv and Zoller, Heather M (2012) 'Dialogue, activism, and democratic social change', Communication Theory, Vol. 22, pp. 66-91.

Guelke, Adrian (2012), Politics in deeply divided societies, Polity Press, Cambridge.

Gürsözlü Fuat (2009), 'Debate: agonism and deliberation-Recognizing the difference', Journal of Political Philosophy, Vol. 17, No. 3, pp 356-368

Healy, Paul (2011), 'Rethinking deliberative democracy: From deliberative discourse to transformative dialogue,' Philosophy and Social Criticism, Vol. 37, No. 3, pp. 295311.

Hirsch, Alexander Keller (2012), 'Fugitive reconciliation' in Alexander Keller Hirsch (ed), Theorizing post-conflict reconciliation, Routledge, London, pp. 79-99.

Holloway, David (2004), A practical guide to dialogue, The Community Dialogue Critical Issues Series, Vol. 2, Critical Dialogue, Belfast.

Honig, Bonnie (1993) Political theory and the displacement of politics, Cornell University Press, Ithaca.

Isaacs, Wiliam N. (1993), 'Taking flight: Dialogue, collective thinking, and organizational learning', Organizational Dynamics, Vol. 22, No. 2, pp. 24-39. 
James, Michael Rabinder (1999), 'Critical intercultural dialogue', Polity, Vol. 31, No. 4, pp. 587-607.

Kahane, Adam (2004), Solving tough problems: An open way of talking, listening and creating new realities, Berrett Koehler, San Francisco.

Little, Adrian (2007), 'Between disagreement and consensus: Unravelling the democratic paradox', Australian Journal of Political Science, Vol. 142, No. 1, pp.14359.

Little, Adrian (2012), 'Rhetorics of reconciliation: Shifting conflict paradigms in Northern Ireland', in Alexander Keller Hirsch (ed), Theorizing post-conflict reconciliation, Routledge, London, pp. 65-78.

Maddison, Sarah (2011), Beyond white guilt, Allen and Unwin, Sydney.

Maoz, Ifat, Bar-On, Dan, Bekerman, Zvi, and Jaber-Massarwa, Summer (2004), 'Learning about "good enough" though "bad enough": A story of a planned dialogue between Israeli Jews and Palestinians', Human Relations, Vol. 57, No. 9, pp. 10751101.

Mouffe, Chantal (2000), The democratic paradox, Verso, London.

Mouffe, Chantal (2005) On the political, Routledge, UK. 
Mouffe, Chantal (2007), 'Democracy as agonistic pluralism', in Elizabeth Deeds Ermath (ed), Rewriting democracy: Cultural politics in postmodernity, Ashgate, Aldershot, pp. 36-45.

Muldoon, Paul (2008), “The very basis of civility": On agonism, conquest, and reconciliation', in Will Kymlicka and Bashir Bashir (eds) The politics of reconciliation in multicultural societies, Oxford University Press, Oxford, pp. 114-135.

Nadler, Arie (2012), 'Intergroup reconciliation: Definitions, processes, and future directions', in Linda R. Tropp (ed), The Oxford handbook of intergroup conflict, Oxford University Press, New York, pp. 3-10.

Nagda, Biren (Ratnesh) A., Yeakley, Anna, Gurin, Patricia, and Sorenson, Nicholas (2012), 'Intergroup dialogue: A critical-dialogic model for conflict engagement', in Linda R. Tropp (ed), The Oxford handbook of intergroup conflict, Oxford University Press, New York, pp. 210-228.

O’Flynn, Ian (2007) 'Divided societies and deliberative democracy’, British Journal of Political Science, 37, 731-751.

Pruitt, Bettye and Thomas, Philip (2007), Democratic dialogue: A handbook for practitioners, General Secretariat of the Organization of American States, International Institute for Democracy and Electoral Assistance, and United Nations Development Programme, New York. 
Ramsbotham, Oliver (2010) Transforming violent conflict: Radical disagreement, dialogue and survival, Routledge, London.

Saunders, Harold H. (2001), A public peace process: Sustained dialogue to transform racial and ethnic conflicts, Palgrave, New York.

Schaap, Andrew (2006), 'Agonism in divided societies', Philosophy and Social Criticsm, Vol. 32, No. 2, pp. 255-277.

Schoem, David, Hurtado, Sylvia, Sevig, Todd, Chesler, Mark, and Sumida, Stephen H. (2001) 'Intergroup dialogue: Democracy at work in theory and practice', in David Schoem and Sylvia Hurtado (eds), Intergroup dialogue: Deliberative democracy in school, college, community and workplace, University of Michigan Press, Ann Arbor, pp. 1-21.

Taylor, Charles (1993) 'The politics of recognition', in Amy Gutmann (ed), Multiculturalism and the politics of recognition, Princeton University Press, Princeton, NJ. pp. 23-73.

Tully, James (2004) 'Recognition and dialogue: the emergence of a new field', Critical Review of International Social and Political Philosophy, Vol. 7, No. 3, pp. 84-106.

Tully, James, (2008) Public philosophy in a new key, Volume 1, Democracy and Freedom, Cambridge University Press, Cambridge UK. 
Walsh, Katherine (2007), Talking about race: Community dialogues and the politics of difference, University of Chicago Press, Chicago.

Wayne, Ellen Kabcenell (2008), 'Is it just talk? Understanding and evaluating intergroup dialogue', Conflict Resolution Quarterly, Vol. 25, No. 4, pp. 451-478.

Yankelovich, Daniel (1999), The magic of dialogue: Transforming conflict into cooperation, Touchstone, New York.

\footnotetext{
${ }^{1}$ Readers interested to know more about the sort of dialogical practices developed by the UNDP should view the extensive range of material, including methodological tools and research and analysis, collected at their website Democratic Dialogue and Conflict Prevention: http://www.democraticdialoguenetwork.org/app/en

${ }^{2}$ The agonistic critique of deliberation, and the responses from deliberative theorists, have been documented extensively in the relevant literature. See for example Little (2007), Schaap (2006), Muldoon (2008), O’Flynn (2007), Dryzek and Niemeyer (2006), and Gürsözlü (2009), inter alia.
} 


\section{University Library}

\section{- M M I N E R VA A gateway to Melbourne's research publications}

Minerva Access is the Institutional Repository of The University of Melbourne

Author/s:

Maddison, $S$

Title:

Relational Transformation and Agonistic Dialogue in Divided Societies

Date:

2015-12-01

Citation:

Maddison, S. (2015). Relational Transformation and Agonistic Dialogue in Divided Societies.

POLITICAL STUDIES, 63 (5), pp.1014-1030. https://doi.org/10.1111/1467-9248.12149.

Persistent Link:

http://hdl.handle.net/11343/292089 